\title{
Citizenship, Social Justice and Collective Empowerment: Living Outside Mental Illness
}

\author{
Graziela Reis $^{1}$ - Billy Bromage ${ }^{1}$ (D) Michael Rowe ${ }^{1}$ (D) $\cdot$ Maria E. Restrepo-Toro' ${ }^{1}$. \\ Chyrell Bellamy' ${ }^{1}$. Mark Costa ${ }^{1}$ (D) . Larry Davidson' ${ }^{1}$ (D)
}

Accepted: 12 December 2021 / Published online: 20 January 2022

(c) The Author(s), under exclusive licence to Springer Science+Business Media, LLC, part of Springer Nature 2021

\begin{abstract}
Citizenship is emerging as one of the world's leading models to shift mental health care from artificial psychiatric settings into more natural community settings by incorporating human rights. This paper describes a four-session roundtable series entitled Citizenship, Social Justice, and Collective Empowerment: Living Outside Mental Illness. These roundtables were part of the New England Mental Health Technology Transfer Center Network (MHTTC). They were built on the conviction that people who have lived experiences of mental health challenges and engaged in making community connections should be at the center of teaching about those experiences. Presenters shared their experiences about how they navigated stigma and discrimination on their way to community inclusion, belonging, and empowerment. The common theme across the series was the citizenship framework. The citizenship framework has inspired people to become involved in an individual and collective dynamic experience that connects them with the 5R's of rights, responsibilities, roles, resources, relationships, and a sense of belonging in society. The outcomes from the discussion on the webinars demonstrated that peer support could be a promising intervention to increase the sense of belonging in the community.
\end{abstract}

Keywords Citizenship $\cdot$ Social Justice $\cdot$ Collective empowerment $\cdot$ Mental Illness $\cdot$ And Recovery

\section{Introduction}

Virtual learning spaces have increasingly been recognized as essential venues for advancing learning and innovation, both in general and between colleagues in specific disciplines or practice modalities. With the onset of the COVID-19 pandemic and the shuttering of in-person training and conferences, virtual learning has played an even more pivotal role. To share innovations and their potential applications with colleagues, practitioners have turned to platforms such as webinars to share new ideas and possible advancements in their fields. When combined with effective communication across broad networks, these learning

Extended author information available on the last page of the article 
opportunities have been shown to have a far-reaching and meaningful impact. The COVID19 pandemic has provided us with a chance to pave the way for introducing digital learning [1].

The New England Mental Health Technology Transfer Center Network (MHTTC) is one of ten regional centers funded by the U.S. Substance Abuse and Mental Health Services Administration (SAMHSA) to disseminate evidence-based practices for mental health conditions into the field. Initiatives developed through this network have focused on mental health prevention, treatment, and recovery supports that are effective, feasible, and needed.

This paper describes a four-session roundtable series entitled Citizenship, Social Justice, and Collective Empowerment: Living Outside Mental Illness. We will discuss perspectives that individual presenters shared when describing aspects of their journeys through the lenses of recovering Citizenship and collective Citizenship. We include composite quotes from each of the four sessions to highlight some of those perspectives. The presenters were invited as panelists on a given webinar based on their previous participation in projects to implement Citizenship in community contexts. Most were people in recovery; some were partners from community-based organizations. Attendees were invited to participate through the New England Mental Health Technology Transfer Center (MHTTC), National MHTTC, PRCH, and presenters' social media.

\section{Citizenship and Recovering Citizenship}

Citizenship is emerging as one of the world's leading models to shift mental health care from artificial psychiatric settings into more natural community settings by incorporating human rights. The framework is based on the 5 Rs of rights, responsibilities, roles, resources, and relationships that society offers its members through public and social institutions and a sense of belonging in a society validated by others [2]. The passage from exclusion to inclusion mediates the passage from the status of patient or client to citizen [3]. In recent years, the citizenship model as practiced and studied at the Yale Program for Recovery and Community Health $(\mathrm{PRCH})$ has been expanded through the related concepts of recovering Citizenship and collective Citizenship.

Recovering citizenship attempts to integrate the concepts of mental health recovery and Citizenship in relation to mental health systems of care by arguing that individuals' recovery occurs in the context not only of recovery-oriented services and supports and a subjective sense of 'being a person in recovery,' but also in relation to one's recognition and participation in society [4]. Collective Citizenship argues that while Citizenship, as defined above, inherently addresses social relationships and social involvement, it has primarily been applied in local mental health care systems that focus on the well-being of individuals. Collective Citizenship focuses on the creative tension between individual and collective approaches to supporting people's empowerment and full membership in the society and on activities and actions in concert with others outside systems of care [5]. Collective Citizenship is the practice by which citizens expand social mobilization, position, and political engagement to create varied ways to act as community builders [6]. The concept has also been adapted for application in South America, Europe, and Asia [7].

Realization of these concepts in innovative community programs involves incorporating values, principles, cultural competencies, and peer support practice. Implementation of citi- 
zenship practice consists in creating opportunities for mutual 'recognition' in such forms as (a) close relations of love and friendship; (b) legally institutionalized relations of universal respect for the autonomy and dignity of persons, and (c) networks of solidarity and shared values within which the particular worth of members of a community can be acknowledged [8] [9]. This approach bears similarities to the ways to social inclusion and full participation in the society described in the recovering citizenship framework. Recovering Citizenship is the process of regaining purpose, meaning, joy in life even if or even though the person continues to experience the symptoms of a mental illness [4].

In 2020, PRCH researchers, peer support workers, and other people with lived experiences of mental illness partnered with community leaders to offer a series of roundtables and webinars. They introduced the collective citizenship framework to the mental health field by highlighting ways in which it has been practiced. Each session engaged presenters and participants in conversations about how collective Citizenship works in their organizations and, more importantly, in their local community outside their organizations. One session, for example, involved how a collective citizenship approach can help providers and clinicians refocus on social justice and social advocacy for their clients. Presenters with mental illness illustrated these 'ways' through vivid examples based on their lived expertise.

The series of webinars offered through the platform of the New England MHTTC described in this paper is built on the conviction that people who have lived experiences of mental health challenges and engaged with recovery and making community connections should be at the center of teaching about those experiences. Presenters shared their experiences about how they navigated stigma and discrimination on their way to community inclusion, belonging, and empowerment. The common theme across the series was the citizenship framework. Each of the four sessions is described in the following section.

\section{Sharing Stories to Build New Perspectives}

\section{The Arts and Social Justice}

The history of human civilization can be told through art, and theater is one way to understand, express, and interpret life. From Greek tragedies to the Theatre of the Oppressed, performances are tools that actors use to embody the experiences of oppression and in societies. Boal created an interactive performance model, Theater of the Oppressed, through which actors and audiences establish a dialogue based on real-life situations. In doing so, he democratized access for minorities to be heard through empowering their voices on issues of equity, social justice, and inclusion. Art, then, can be socially and politically liberating and can exemplify power relationships that aim to meet people's need for dialogue, critical thinking, and, furthermore, fun [10]. 'Art in mental health' creates a space in which people with lived experience of mental illness can find value and become active members of society rather than passive recipients of care. The relationship between patients and clinicians in psychiatric settings is primarily based on illness. In art, illness is represented by people and offers a broad view of the person. In art, illness is fiction, and people are citizens.

The first webinar in the Citizenship, Social Justice, and Collective Empowerment series featured a director from the Theater of the Oppressed in New York City and two people in recovery. The latter acted in several of the Theaters' productions in New Haven, Connecti- 
cut. The moderator was the communications director of the local community mental health center, who is also a member of the team implementing citizenship practices and has been instrumental in building and sustaining the working relationship between Theater of the Oppressed and people in recovery in New Haven. Presenters who led this session spoke of self-disclosure:

"From my point of view, as a theater actress, art is a way that I can express myself outside of my body. It isn't for people to understand you. It is for you to understand yourself better. It is crucial for people to express themselves through art. I use art to talk about mental illness and express myself. I talk about stigma reduction in people's minds. In doing that, happiness and joy came to me. I was afraid when I started. Making friends was important to me. I realized that art impacts people's life. It also impacts my life. I appreciated being part of the group. I saw doctors, clinicians, and community members in the audience listen to my story. It is a true-life story. I feel healing when I am interpreting my story. Art creates advocacy. This is the power of the work, to tell about the system and how it does not work sometimes. The limits become a possibility. We can create a problem and a solution together. Your interpretation introduces a problem, how you can solve it shows people that doing things together creates better solutions. It is a dialogue that includes everyone. It is recovery and belonging." (presenters during New England MHTTC roundtable).

The recovering citizenship model argues that people have a rightful place as a valued participant in society. This truth lies at the core of each person's unique journey to life as a citizen [4]. Honneth claims that a society in which individuals have a real opportunity for self-realization would be a society in which they hold some common values [8]. Citizenship and social justice frameworks can employ art to support people with serious mental illnesses in creating new roles for themselves in society while simultaneously challenging people in the audience to reimagine their views of mental illness, recovery, and Citizenship. Doing so enhances people's self-confidence and evokes powerful feelings in them to nurture new relationships with others that are vital to personal growth.

\section{The Citizenship Framework and Community Building}

Collective action requires individuals to "sign on" to a collective hope process through sharing a vision of desired social change and seeing the opportunity for its realization [11]. Members of the Focus Act Connect Every-day (FACE) group developed a program for building networks and making a community-level change outside of mental health settings. Community-focused care is that which (1) is primarily provided in a person's natural community; (2) facilitates the development of relationships with people in one's community; (3) helps people enhance their Citizenship by taking on valued roles in their communities; and (4) works with members of the general community to combat stigma and increase access to resources [12]. Peer support professionals and community activists have demonstrated that community building and active Citizenship can play an essential role in recovery [13].

The panel for this webinar consisted of people representing a diverse array of roles in community-building in the West River neighborhood in New Haven, Connecticut: a peer support professional, a man in recovery who has been a community activist for many years, a long-time mental health and community advocate, and the neighborhood association presi- 
dent. All the panelists except one were people in recovery and members of FACE. The moderator was one of the authors of this article (BB). He used his experiences of linking FACE to the West River community to guide the conversation. Presenters shared interpretations of activism and legitimated their identity from the past to build community in the present:

"I have been active in my community for a long time. The idea of bringing the community together was there. The challenge was how to put the community together. We started with the FACE project. We moved around New Haven, we met in different places, and the city started to know what we were doing. People of color, people with mental illness, the homeless, and community leaders came and signed on to promote the change. Then, we started to promote the change and live everyday life. We meet and talk about what we need, what we want, and what comes from our hearts. We aren't alone, and we grow together during this process. We get together to share decisions positively and vibrantly. This makes me come back because we don't talk about our mental illness or substance use, even if I still have it with me. We are validated, and we have a voice. FACE is a place where people look for change. It is a place to belong." (presenters during New England MHTTC roundtable).

Research on recovery teaches that retrieving one's life does not occur in a straight upward path (any more than it does for those without mental illness) but occurs in stages, with stops and starts, with progress and setbacks [14]. At the same time, the citizenship framework has inspired people to become involved in an individual and collective dynamic experience that connects them with the 5R's of rights, responsibilities, roles, resources, relationships, and a sense of belonging in society [2]. Recognition must come from other members of society. The status of a positive sense of belonging is a powerful tool to improve well-being. FACE makes a significant contribution to promoting changes and sharing ways to live more positive lives.

\section{The Essential Role of Peer Support in Citizenship Work}

Peer support has been present in the mental health field since the 18th century as a supportive and humane approach when the Bicetre Hospital in France sought to employ as many ex-patients as possible because they were considered gentler and more humane than caregivers [15] [16]. It first appeared in North America in the $1920 \mathrm{~s}$ in a psychiatric hospital [17] [16]. In the early $1930 \mathrm{~s}$, peer support became the centerpiece of Alcoholics Anonymous, and the peer-led psychosocial clubhouse model began in the late $1940 \mathrm{~s}$ [18] [16]. In the 21 st century, peer work in mental health services has become an essential and valuable service delivery component [19] [20] [16]. Along with supporting people in service settings, peer supporters support people in living a full life in their community outside of the mental health system.

This webinar was a conversation between peer support professionals across Connecticut who play various roles, including working in a direct service setting, advising the state mental health authority, community and systems-level advocacy, and community organizing and citizenship interventions. The panel also included a woman in recovery who shared her experiences working with peer support professionals, primarily in non-clinical community settings. The following are some of the key points discussed during this webinar: 
"I know from my personal lived experience as a recipient of peer support in my life what 'peer' means. My peer holds my hand and guides me to take responsibility in my recovery process. Peer support empowers people to live a whole life. The mental health system doesn't offer many things to you. The presence of peers in my life came from a program outside the mental health system. Being a person who has lived experience and having a peer help me become the person I am today. I am a professional; I am a student. Having a peer was a good way to educate me and turn things around for me. It is great to interact with people who help you increase hope, feel included in your community, and advise you on your state of needs. Peers work with people on a humanity level. This is an everyday reminder. After a long-time of work as a peer, I realized that you need to be aware not to become a case manager. Peers work with recovery principles and competencies. We promote citizenship inclusion and belonging. We share with clinicians the lived experience of mental illness through our lens. We promote cultural changes being in our role." (presenters during New England MHTTC roundtable).

Peer supporters are trained to connect with other people in recovery by sharing their lived experiences in ways in which many providers are not trained to do [21]. Peers draw on their life experience to develop meaningful connections with people, listening to them, reflecting, reframing, and sharing resources available within the mental health system and, more importantly, through community-based programs and organizations. Citizenship argues that systems of care alone can never support the full community membership of the people they serve. Further, Citizenship acknowledges that interventions at the margins of mental health systems of care and the broader community are needed to bridge the gap between the two [2] [5, 14]. In this sense, peer support involves developing an authentic connection with others that underpins trust, mutual involvement in decision-making, empowerment, community engagement, meaningful relationships, and respectful communication with the essential people in one's life.

\section{Advocacy and the Citizenship Framework}

Influenced by Nietzsche's work, Foucault wrote in the History of Madness that we must talk about madness without silencing it, without pulling out the power of its language [22]. To talk about madness, it is necessary to understand it. For many years people with mental illness were silenced and locked up in asylums. It was essential for those silenced by traditional psychiatric treatment to find their collective voice in an anti-asylum movement that ushered in a new era. This movement inspired people worldwide and potentiated a second radical mental health movement in the United States. The recovery movement has had a profound impact on the mental health field. It was recognized as a consumer-led advocacy movement that promoted changes in the societal conditions and oppressive structures that impact the mental health system and people with lived experience. More recently, the concept of Citizenship has begun to articulate the nature of the responsibility the community bears in promoting recovery per se and affording persons with serious mental illness full Citizenship as a foundation for recovery [4]. The antidote to silencing people is to support empowered spaces in which they can speak up and advocate for themselves and others. Such areas also support helping people with lived experience take their places at the center of discussion about mental health through sharing their own life stories and becoming activ- 
ists. The citizenship framework has promoted changes through collective efforts that impact the work outside the mental health system [5].

The final webinar in the four-part series focused on advocacy and its role in catalyzing individual and community-level change. The panelists included members of Witnesses to Hunger, an anti-hunger advocacy group in New Haven led by people with firsthand experiences of poverty and marginalization. Panelists were all people in recovery and included the organization's leader, two peer support professionals who are also community advocates, and a man in recovery who is an artist and a co-founder of FACE. One of the authors of this article (BB), who has supported Witnesses to Hunger in various ways since its inception, moderated the webinar.

"I became homeless, and I got accepted to a transitional housing program. I started to attend meetings that we're offering on this program. I started to get involved, and we organized ourselves to share our stories with legislators. This experience was powerful because they started to hear our voices. At this time, I started my activism. Many families are struggling with their personal experiences. Advocacy was how to talk about my life story and combine my own experience with my professional life. In doing that, I created opportunities to guide other families, and many other life experiences were shared and heard. Being an activist for me was very empowering and brought me to where I am now. Becoming a peer mentor was the way to be an activist who advocates for anyone. I was confident to speak to others when I became confident to speak for myself. We advocate for changes in our life and community. People with lived experience should be at the table to tell their own life stories and shift ways to change society more positively. We are not alone-people and power!" (Presenters during NE-MHTTC roundtable).

In The Human Condition, Hannah Arendt helps us understand the importance of public space as a political space. For Arendt, everything that becomes public can be seen and heard by everyone. It is through the use of public spaces that transformations occur. The most common of these transformations occur through storytelling and the transmission of individual experiences. When we encourage someone to talk about their story, we encourage the practice of Citizenship: every time we share stories of life that were experienced in private, we make them public, authentic, and powerful. In the presence of others who see what we see and who hear what we hear, we ensure the reality of our world and ourselves [23].

\section{Conclusions}

\section{It is us, all of us}

It is increasingly recognized that arts participation by people with lived experience has facilitated recovery through social inclusion. Art has the potential to shift the current narrow focus of biomedical mental health care into a redefinition of the clinical understanding of recovery. Recovery thus conceived includes Citizenship and belonging and relocates those who have lived experience as the drivers of their own lives [24]. The four experiences described in this article illustrate social inclusion, Citizenship, advocacy, community engagement, human rights, and empowerment are at the center of individual choices. Rowe 
and Davidson (2016) define "recovering citizenship" as a concept and metaphor to capture the individual recovery process within a social context [25].

Studies about recovering citizenship focus on how equal opportunities and belonging can be offered to people experiencing mental health struggles and all members of any society. This approach merges the individual strengths of the recovery and Citizenship approaches with the simultaneous rise of personal and cultural identity, lifestyle, values, and social justice to make life possible outside the mental health system. Recovering Citizenship is about social inclusion and the full participation of individuals with mental illness in society and about individual and collective efforts to support ethical and collective responsibility [5].

Developing community support groups that can support as a recovery journey from individualism to collectivism is one of many ways to use the citizenship approach. Collective citizenship practice provides the group experiences and cohesion that individuals require as social beings [5]. Analysis of a longitudinal randomized controlled trial of a citizenshipbased intervention showed that participants had significantly greater increases in quality of life, amount of and satisfaction with their activities, satisfaction with work, and satisfaction with their ones' finances than those who did not receive the intervention [26]. Participants in projects and programs employing the recovering-citizenship approach identify new forms of involvement in the community that is accessible, take account of their needs, and include them in decision-making. Increasing solidarity with groups who have been marginalized and oppressed and taking collective action to address the root causes of that marginalization and oppression are essential dimensions of community involvement. They should be expanded within the citizenship framework [5]. Supporting and engaging with groups led by people in recovery and others facing social inequities such as Witnesses to Hunger, the group discussed in the final webinar in the series, is an essential step for aligning Citizenship with organized social action.

This paper develops and proposes a conceptual framework suggesting that collective Citizenship and recovery could promote human connections that may contribute to engaging community members in proactive community life. One strategy that was collectively adopted was to connect people who have lived experience with peer support. The involvement of peers generated many benefits (health, financial, emotional, spiritual, social, and environmental) that contributed to individual and collective interactions. The outcomes from the discussion on the webinars demonstrated that peer support could be a promising intervention to increase the sense of belonging in the community. During the webinars, peers shared the benefits of recovery and citizenship community programs on the lives of individuals returning with mental illness back to their communities [27].

Supplementary Information The online version contains supplementary material available at https://doi. org/10.1007/s11126-021-09968-x.

Acknowledgements The authors gratefully acknowledge Lucile Bruce, Liz Morgan, Al Gamble, Shannon Smith, Bob Forlano, Bridgett Williamson, Paul Acker, Virginia Spell, Marcus Griffin, Kim Hart, Annette Diaz, Cheri Bragg, and Do Walker, for their contributions to the MHTTC - New England, webinar series: Citizenship, Social Justice and Collective Empowerment: living outside mental illness.

Funding Information The opinions expressed herein are the views of the authors and do not reflect the official position of the Department of Health and Human Services (DHHS), or Substance Abuse and Mental Health Services Administration (SAMHSA). No official support or endorsement of DHHS, SAMHSA, for the opinions described in this article is intended or should be inferred. This work is supported by grant 1H79SM081775 from the DHHS, SAMHSA. The work described in this article was founded in part by the 
State of Connecticut, Department of Mental Health and Addiction Services, bit this publication does not express the views of the Department of Mental Health and Addiction Service or the State of Connecticut. The views and opinions express are those of the authors.

Disclosures The authors declare that they have no competing interests.

\section{References}

1. Dhawan, S. Online learning: A panacea in the time of COVID-19 crisis. J Educ Technol Syst. 2020;49(1):5-22.

2. Rowe, M. Citizenship and mental health. USA:Oxford University, Press; 2015.

3. Atterbury, K. and Rowe,M. Citizenship, Community Mental Health, and the Common Good. Behav Sci Law. 2017;35(4):273-287.

4. Rowe, M. and Davidson, L. Recovering Citizenship. Isr J Psychiatry Relat Sci. 2016;53(1):14-20.

5. Quinn, N., Bromage, B. and Rowe, M. Collective citizenship: From citizenship and mental health to citizenship and solidarity. Soc Policy Adm. 2020;54(3):361-374.

6. Escoffier, S. Mobilisational citizenship: sustainable collective action in underprivileged urban Chile. Citizensh Stud. 2018;22(7):769-790.

7. Bromage, B., et al. International perspectives on a collective approach to recovery and citizenship Cadernos Brasileiros de Saúde. Ment/Brazilian J Ment Health. 2021;13(35):01-15.

8. Anderson, J. Translator's Introduction to Axel Honneth, The Struggle for Recognition: The Moral Grammar of Social Conflicts.1995.

9. Petherbridge, D. Recognition, Vulnerability and Trust. Int J Philos Stud. 2021;29(1):1-23.

10. Wasylko, Y. and Stickley, T. Theatre and pedagogy: using drama in mental health nurse education. Nurse Educ Today. 2003;23(6):443-8.

11. Braithwaite, V. The hope process and social inclusion. Ann Am Acad Pol Soc Sci. 2004;592(1):128-151.

12. Lightburn, A. and Sessions, P. Handbook of community-based clinical practice. Oxford University Press; 2006.

13. Cruwys, T., et al. The recovery model in chronic mental health: A community-based investigation of social identity processes. Psychiatry Res. 2020;29:1113-241.

14. Bromage, B., et al. Project Connect: A community intervention for individuals with mental illness. Am J Psychiatr Rehabil. 2017;20(3):218-233.

15. Weiner, D.B. The apprenticeship of Philippe Pinel: a new document, "observations of Citizen Pussin on the insane". Am J Psychiatry. 1979;136(9):1128-34.

16. Cleary, M., et al.'Walking the tightrope': The role of peer support workers in facilitating consumers' participation in decision-making. Int J Ment Health Nurs. 2018;27(4):1266-1272.

17. Davidson, L., et al. Peer support among persons with severe mental illnesses: a review of evidence and experience. World Psychiatry. 2012;11(2):123-8.

18. Raeburn, T. Rehabilitation Groups, In: Oxford Research Encyclopedia of Communication; 2017.

19. Kilpatrick, E., S. Keeney, and McCauley, C.O. Tokenistic or genuinely effective? Exploring the views of voluntary sector staff regarding the emerging peer support worker role in mental health. J Psychiatr Ment Health Nurs. 2017;24(7):503-512.

20. Simmons, M.B., et al.The Choice Project: Peer Workers Promoting Shared Decision Making at a Youth Mental Health Service. Psychiatr Serv. 2017;68(8):764-770.

21. Bellamy, C., T. Schmutte, and Davidson, L.An update on the growing evidence base for peer support. Mental Health and Social Inclusion; 2017.

22. Elden, S. The Early Foucault. John Wiley \& Sons; 2021.

23. Arendt, H. The human condition. University of Chicago Press; 2013.

24. Sapouna, L. and Pamer, E. The transformative potential of the arts in mental health recovery-an Irish research project. Arts Health. 2016;8(1):1-12.

25. Pelletier, J.F., et al. Citizenship and recovery: two intertwined concepts for civic-recovery. BMC Psychiatry, 2015;15:37.

26. Clayton, A., et al. The Citizenship Project part II: impact of a citizenship intervention on clinical and community outcomes for persons with mental illness and criminal justice involvement. Am J Community Psychol, 2013;51(1-2):114-22.

27. Bellamy, C., et al. Peer support on the "inside and outside": building lives and reducing recidivism for people with mental illness returning from jail. J Public Ment Health. 2019. 
Publisher's Note Springer Nature remains neutral with regard to jurisdictional claims in published maps and institutional affiliations.

\section{Authors and Affiliations}

\section{Graziela Reis ${ }^{1}$ Billy Bromage ${ }^{1}$ Michael Rowe' $\cdot$ Maria E. Restrepo-Toro ${ }^{1}$. Chyrell Bellamy ${ }^{1} \cdot$ Mark Costa $^{1} \cdot$ Larry Davidson $^{1}$}

Graziela Reis

graziela.reis@yale.edu

Billy Bromage

billy.bromage@yale.edu

Michael Rowe

michael.rowe@yale.edu

Maria E. Restrepo-Toro

maria.restrepo-toro@yale.edu

Chyrell Bellamy

chyrell.bellamy@yale.edu

Mark Costa

mark.costa@yale.edu

Larry Davidson

larry.davidson@yale.edu

1 Department of Psychiatry, Yale Program for Recovery and Community Health (PRCH), Yale School of Medicine, New Haven, CT, United States 